\title{
The Effect of Translating Specialized Vocabulary into Plain English in the courses of Food Fermentation and Brewing
}

\author{
LI Guijie ${ }^{1, a}$, SUN Peng ${ }^{1, b^{*}}$, WANG Qiang ${ }^{1, ~ c}$, ZHAO Xin ${ }^{1, d}$ and LI Dan ${ }^{2, \text { e }}$ \\ ${ }^{1}$ Department of Biological and Chemical Engineering, Chongqing University of Education, 400067 \\ Chongqing, China \\ ${ }^{2}$ Preschool Education College, Chongqing University of Education, 400067 Chongqing, China \\ aquajetlee@gmail.com, b598535244@qq.com, ' 90 go1443@qq.com, dfoods@live.cn, \\ edannalee95@gmail.com \\ *Correspondent author
}

Keywords: Specialized vocabulary. Anglicization. Food fermentation and brewing.

\begin{abstract}
This study aimed to explore how the translating of traditional scientific vocabulary into plain English influences student achievement in food fermentation and brewing university courses. The Data were collected from course sections instructed with traditional vocabulary, which is only translated and explained by Chinese, as well as sections instructed first with plain-English equivalent terms and then Chinese. The both treatment groups followed the same inquiry-based curriculum. The results showed that while different groups gained similar scores in basic knowledge and experimental ability, the plain English instructed students showed significantly better performance in the comprehensive written exams of food fermentation and brewing when compared to peers instructed with traditional vocabulary. The results supported the validity of the instruction methodology which relating unfamiliar new words to familiar known words.
\end{abstract}

\section{Introduction}

This study seeks to assess and quantitatively evaluate a method by which university teachers may make their courses more effective and accessible to undergraduate. The method under examination utilizes pedagogical techniques to examine the effect of inquiry-based learning and vocabulary modification on student outcomes in Food Fermentation and Brewing (FFB) course. The main objective of this study was to investigate if the translation of scientific and technological special vocabulary terms to plain English, a process that will henceforth be referred to as Anglicization, would work on student learning within the course context. The specific vocabulary of food microbiology, fermented food processing and traditional brewing which are derived from the Classical languages was Anglicized whenever possible (Table 1 as an example).

\begin{tabular}{cc} 
Table 1 Traditional and Anglicized equivalent terms instructed in FFB course \\
\hline Traditional term & Anglicized term \\
\hline Hydrate & Compounds that contains water \\
Lipid & Fat and oil \\
Inoculate & Put into \\
Anaerobe & Oxygen-intolerant \\
Thermophile & Warmth-loving \\
Biogenic & Produced or originated from a living organism \\
Saccharification & Degrade into sugar \\
\hline
\end{tabular}

There are many reasons to expect that the modified terms will enhance learning. Academic vocabulary has been found to cause difficulties to students, even those who are experienced in other forms of English [1, 2]. For many students, a huge block in the way of building concepts of sciences 
including fermented food can be the acquisition of subject-specific vocabulary. Previous research showed that students learn and retain concepts better when exposed to ideas before the related vocabulary terms are introduced [3]. An anglicized processing will be a potential method that presents information in this format.

\section{Subjects and Methods}

One hundred and thirty four college students from two universities that were enrolled in food fermentation and brewing courses were studied as the subjects. They were all majoring in food sciences and representing diverse ages and nationalities. Slightly more than half of students were female. None of the students speak English as their native or first language. None of them had physical or mental disease.

The course was inquiry-based. The textbooks and syllabus of the two universities and the class content and duration for courses at every parallel class were made as similar as possible. Assessments and curricula for both theoretical and experimental courses were identical. Students entering the course were not expected to have prior training in food fermentation and brewing. While in the course, students are expected to learn introductory information and terms related to the food microbiology, food fermentation and traditional brewing, and to develop knowledge of lab techniques.

Trials involved four classes, two of which were assigned to the experimental groups (i.e. Anglicized treatment) and the other two to the control groups (i.e. traditional treatment). In all cases, treatment and control status were randomly assigned. Efforts were made to eliminate variables other than vocabulary learning between the two treatments. For example, one instructor taught all Anglicized and Classical classes in each university; guidelines and activities were followed as closely as possible between treatments and for each trial.

Content validity was established by a panel of teachers. Examination reliability was established by similar mean scores generated, per treatment, by students across all three trials. Cronbach's alphas were obtained for each test and they all showed good reliability.

Vocabulary Examination. An exam including Chinese-English translation and vice versa and crossword puzzles was used to assess the acquired vocabulary. A crossword puzzle is shown in Fig. 1.

Laboratory Practical Examination. Practical exams assessed some basic technical skills, including isolation streaking of bacteria, aseptic technique, saccharification of raw material, fermenter control and product inspection. Scores were awarded based on notes taken during students' performances.

FFB Knowledge Survey. Identical pre- and post-course microbiology knowledge surveys were administered. Each survey consisted of 10 Bloom knowledge level multiple-choice items. Representative items follow:

1. Which chemical(s) in hops is considered not to play important roles in beer brewage?
(a) $\alpha$ acid
(b) $\beta$ acid
(c) natural phenols
(d) phytoestrogen
(a) rennin
(b) hexosaminidase
(c) glucoamylase
(d) lipase

2. What enzyme is mostly used in the cheese production? 
Fig. 1 Example crossword puzzle used in vocabulary exam

\section{Fermentation and Brewing}

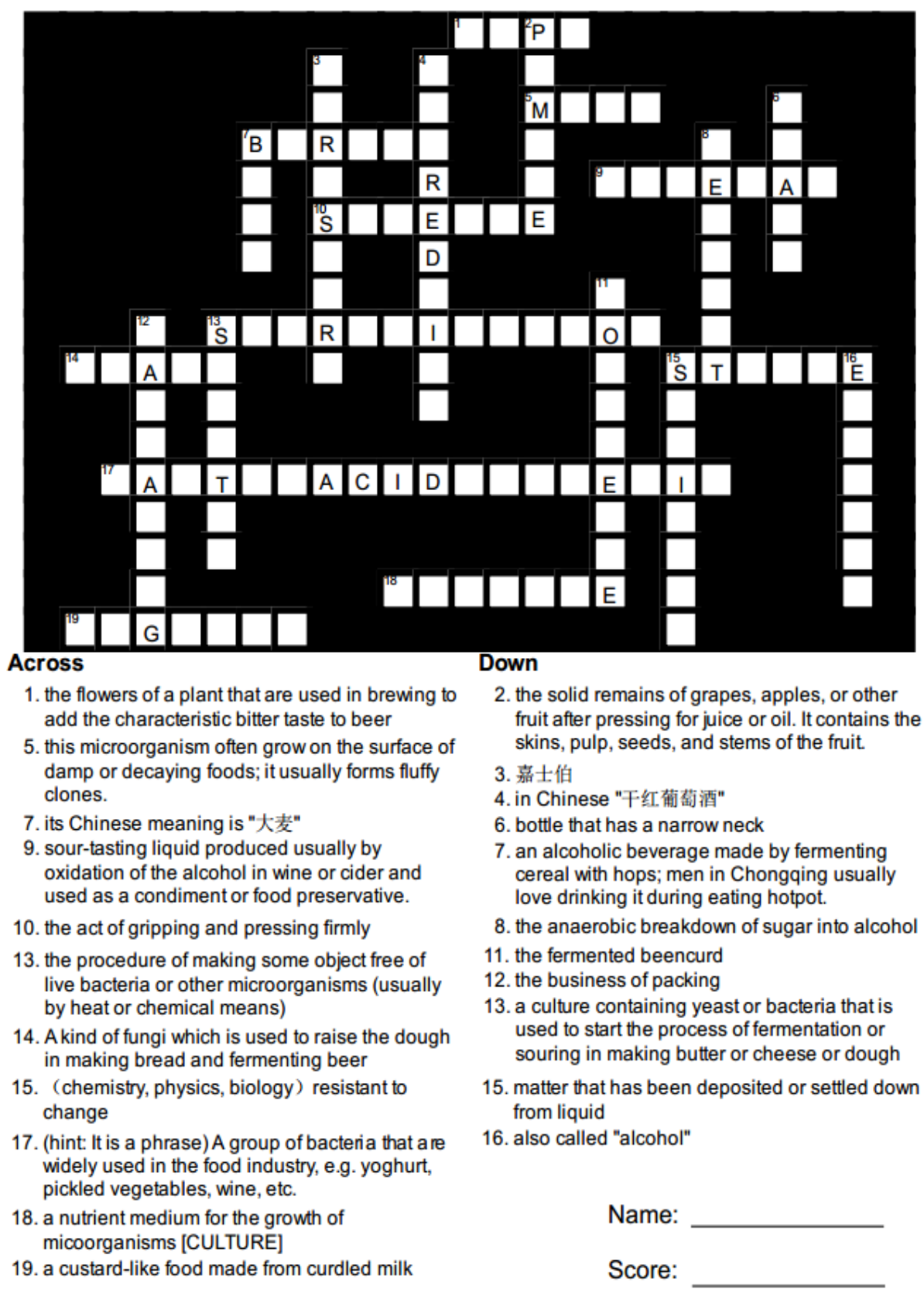

Comprehensive Examinations. Students in Anglicized and Classical treatments were administered two examinations i.e. mid-term and final exam during the semester. Examinations were identical for both Anglicized and Classical sections. The assessments included items administered primarily at Bloom's analysis and application levels. Questions were written so as not to include Anglicized or Classical vocabulary terms, but to elicit such terms as responses. Example items follow:

1. In order to increase the ethanol content of red wine by $1 \%$, how many grams of cane sugar need be added to the fermenter?

2. Xiao Ming is a fan of yogurt self-making. He usually uses Tianyou Milk as the media to produce set yogurt and it turns to be very successful. This time he turned to Yili Milk, adding some fruit crush and aiming to make stirred yogurt, however, he failed. The yougurt did not clot and showed whey off 
phenomenon. Suppose the strains were the same ones as before, do you think what could be responsible for the failure?

Randomly mixed all exam papers from the two treatment groups together and then blindly score; each student's identity and treatment group were. Grading was based on accurate understanding and reasonable application of the knowledge obtained in the FFB courses.

\section{Results and Discussion}

Anglicization Does Not Result in Differential Vocabulary Knowledge Recall. Vocabulary examination score is concordant similar between Anglicized and Traditional treatments in all four trials and for pooled data. The first two trials were operated at one university while the other two trials took place at the other university. Differences between the treatments were non-significant in all cases (Trial 1, $\mathrm{t}=0.49, \mathrm{df}=28, \mathrm{p}>>0.05$; Trial 2, $\mathrm{t}=0.53, \mathrm{df}=27, \mathrm{p}>>0.05$; Trial 3, $\mathrm{t}=0.88, \mathrm{df}=$ 33, $\mathrm{p}>>0.05$; Trial 4, $\mathrm{t}=0.71, \mathrm{df}=39, \mathrm{p}>>0.05$; pooled data, $\mathrm{t}=0.62, \mathrm{df}=133, \mathrm{p}>>0.05$ ). Previous research indicated that students retain information far better when exposed to concepts before they are taught vocabulary words [3]. An Anglicized introductory course would allow students to be presented information in this format. However, as the subjects in this study are non-native English speakers, each student must pay certain time and effort to recite and recall the exact spelling of the specific words and terms; whether the subject was opposed to the plain English translation and hence had a good understanding of their meaning may not be critical to effect in good memorization.

Anglicization Does Not Lead to Significant Difference in Lab Practical Knowledge and Skills. Lab practical examination performance also shows consistently similarity between Anglicized and traditional treatments in all four trials and for pooled data. Differences between the treatments were non-significant in all the cases, i.e. Trial $1, \mathrm{t}=0.16, \mathrm{df}=28, \mathrm{p}>>0.05$; Trial $2, \mathrm{t}=0.38, \mathrm{df}=27, \mathrm{p}>>$ 0.05; Trial 3, $\mathrm{t}=0.28, \mathrm{df}=33, \mathrm{p}>>0.05$; Trial 4, $\mathrm{t}=1.7, \mathrm{df}=39, \mathrm{p}>0.05$; pooled data, $\mathrm{t}=0.81, \mathrm{df}=$ $133, \mathrm{p}>>0.05$. In this case, learning of basic lab techniques and skills, the importance is still following and recalling: remembering previously learned material (for example, the procedure of experiment, or some specific technique and handcrafting). It merely requires bringing to mind the more appropriate information or better understanding of the concept, which may give the hint why Anglicization did not work effectively again.

Similar FFB Knowledge Gains are shown between the two treatments. Both Anglicized and traditional treatment groups made significant pre- to post-test FFB Bloom knowledge level gains: Anglicization, $\mathrm{t}=1.86, \mathrm{df}=80, \mathrm{p}<0.05$, Cohen's $\mathrm{d}=1.13$; traditional teaching, $\mathrm{t}=3.40, \mathrm{df}=100, \mathrm{p}$ $<0.01$, Cohen's $\mathrm{d}=1.01$. A comparison of group gains revealed no significant difference, as $\mathrm{p}>>$ 0.05 . The FFB knowledge is taught not only by English but mostly by Chinese, thus the students can master the basic information easily ignoring accurate understanding and mastering of the English terms.

According to the levels of Bloom's Taxonomy, the mastering of knowledge include 5 levels: recall, comprehension, application, analysis and synthesis. The above mentioned examination, no matter the tests of vocabulary, lab operating ability or basic knowledge comprehension, are included in the first two levels of the progress in Bloom's table. The results show that the plain English instructed students gained similar amounts of lower-order knowledge during the FFB course when compared to peers instructed with standard/traditional vocabulary.

Anglicized Vocabulary Promotes Scores of comprehensive Examination. The means and standard deviation for all two course examinations within all four trials are shown in Fig. 2 . The Anglicized treatment groups consistently outperformed the traditional treatment groups in all four trials. At the same time, all data were pooled across trials. The result shows that the pooled mean scores of the Anglicized treatment groups were significantly higher than those of the traditional 
treatment groups for all two exams (Exam 1, t $=2.36, \mathrm{df}=130, \mathrm{p}<0.05$; Exam 2, $\mathrm{t}=1.99, \mathrm{df}=117$, $\mathrm{p}<0.05)$.

Fig. 2 The mean scores of the comprehensive exams in four trials (SD not shown)

Traditional

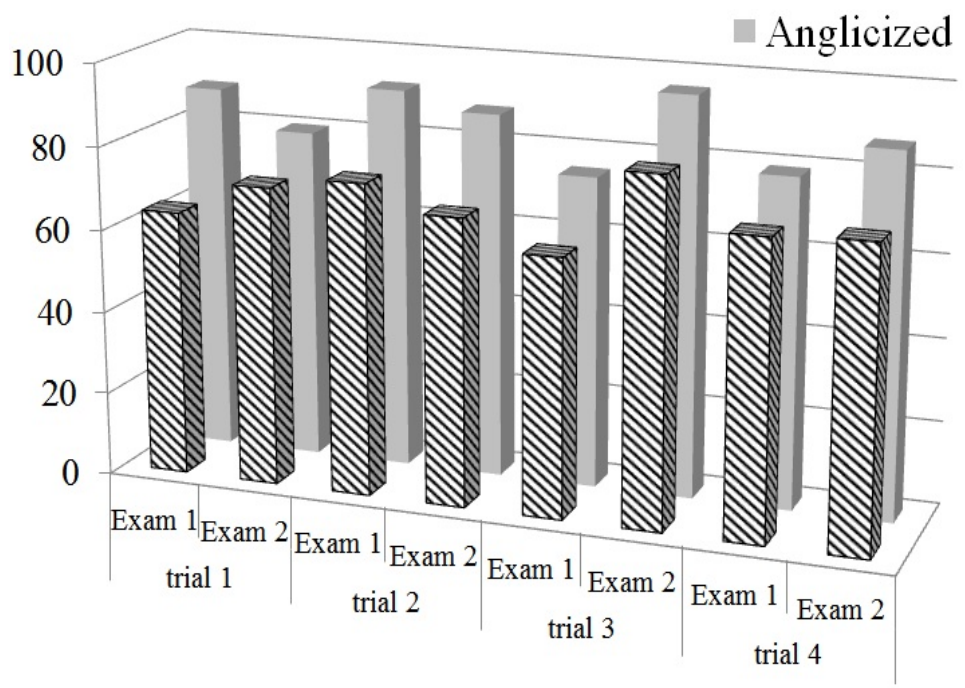

As the written examinations include items mostly administered primarily at Bloom's analysis, application and synthesis levels, the results suggest that the students subjected to Anglicization instruction performed significantly better at higher-order learning abilities from the FFB course. Vocabulary Anglicization which seek to relate unfamiliar new words to familiar known words share some similarity with the mnemonic instruction which has been shown to greatly increase student retention of information compared to students who studied new terms using self-determined methods [4]. Mnemonic instructions are also shown to improve the ability of students to apply the basic knowledge to answer higher-order questions [5], resulting in an improved ability to transfer knowledge to new contexts $[6,7]$. It is noticed that some students have the perception of sciences as an inherently exclusive field. The use of plain-English translation can help reduce the degree of this perception, and thus may alleviate the repression and exclusion feeling in the classroom, leading to an inclusive class atmosphere.

\section{Summary}

The results of this experiment supported the validity of the instruction methodology, Anglicization, in which the unfamiliar new words are related to familiar known words. The use of Anglicized vocabulary has been found to provide significant benefits to students as it enhances their ability to utilize higher-order learning skills. Anglicization can be utilized in the introductory specialized English Session of Food Fermentation and Brewing Course, making the FFB courses more effective and accessible to undergraduate students and thus better preparing them for future professional and educational opportunities.

\section{Acknowledgement}

This research was funded by the Teaching Reform Project of Chongqing University of Education (No.JG201234).

\section{References}

[1] C.E. Snow: Sci. Vol. 328 (2010), pp. 450-452 
[2] A. Bailey: The language demands of school: Putting academic English to the test (Yale University Press, New Haven, CT, USA 2007).

[3] A.E. Lawson: The neurological basis of learning, development, and discovery: Implications for science and mathematics instruction (Kluwer Academic Publishers, London, England 2003).

[4] R.N. Carney: Am. Edu. Res. J. Vol. 25(1) (1998), pp. 107-125.

[5] R.N. Carney and J.R. Levin: Appl. Cog. Psyc. Vol. 17 (2003), pp. 563-575.

[6] B.J. Dretzke: Contemp. Edu. Psyc. Vol. 21 (1996), pp. 83-93.

[7] R.N. Carney: J. Edu. Psyc. Vol. 92(4) (2000), pp. 783-790. 